\title{
Management of Rheumatoid Arthritis 2012: A Canadian State of the Art
}

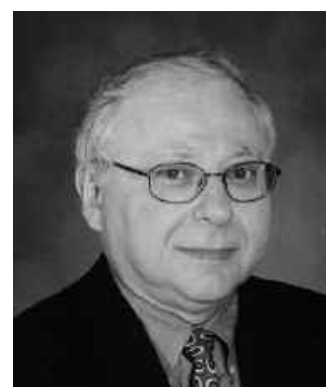

Our thesis is that there is no specific therapy for rheumatoid arthritis. With early diagnosis, simple conservative measures plus salicylates can be so effective that there is little need to utilize more potent pharmacologic therapy with the attendant increase in danger.

These words were one man's opinion of the state of the art of the treatment of rheumatoid arthritis (RA) in $1966^{1}$. Whether one agreed completely with that opinion or not in $1966^{2}$, it needs to be acknowledged that the opinion was well argued and informed by a thorough, albeit not systematic, review of the literature of the time. The author found the published evidence on salicylates and personal experiences with bed rest convincing, decried the lack of well-done randomized clinical trials evaluating gold, noted that any longterm benefits of gold were not sustained, and concluded that the lack of sustained effect coupled with the well-known toxicities of gold could not justify its use. This opinion (level II/III evidence) led to a course of action (strength of recommendation $\mathrm{C}, \mathrm{D}$ ).

In the past 3 years, patients have been adequately managed with bed rest, salicylates, and physiotherapy at the Massachusetts Memorial Hospitals and Boston City Hospital. Indeed, gold salt therapy has not been used by any of a large group of Arthritis Clinic Staff Physicians in these clinics, and no patient has been started on this form of treatment.

Revisiting the issue of care of RA in 1974, the editors opined that no developments had occurred to alter the conclusions of $1966^{3}$.

Since 1974, the development of numerous effective drugs to treat RA has evolved into our current action, the strategy of treating to a target ${ }^{4}$. Targeted care is designed to minimize the time a patient spends on inadequate care. Well-conducted clinical trials examining such strategies repeatedly have demonstrated benefits in controlling measures of disease activity and halting radiographic progression. Targeted care requires a commitment by the treating rheumatologist to measure disease status at frequent intervals, about every 1 to 3 months, and to alter therapy if the target has not been met. In following such a strategy, patients with RA are expected to be exposed to one or more traditional nonbiologic disease-modifying antirheumatic drugs (DMARD), with or without a concomitant biologic DMARD.

In a tour de force, the Canadian Rheumatology Association (CRA) has developed evidence-based recommendations for the pharmacologic management of RA with traditional and biologic DMARD, published in 3 parts.

The strength of the recommendations is firmly rooted in the methods used to generate the recommendations. First, the recommendations are written in response to a needs assessment by treating Canadian health professionals ${ }^{5}$. Treating professionals, not the authors, identified the issues for guideline development. While the perspective is clearly Canadian, the guidelines can be generalized to many other countries. Second, the guidelines are based on a comprehensive search of the international literature. The authors did not re-review the original studies but analyzed international clinical practice guidelines (CPG) and consensus statements (CS) with recommendations for traditional and biologic DMARD licensed for use in Canada for adult patients with RA. An ADAPTE framework was applied to modify international guidelines for use in the Canadian healthcare context ${ }^{6}$. Third, guideline quality was assessed using the validated Appraisal of Guidelines Research and Evaluation (AGREE) instrument ${ }^{7}$. Fourth, a working group of 16 Canadian stakeholders including patient consumers were involved in each step of guideline development. No representatives of pharmaceutical companies were involved in the process.

The articles read easily. Each recommendation is suc-

See Recommendations for management of RA, pages 1555, 1559, and 1583 
cinctly written, a level of evidence and strength of recommendation assigned, a summary of evidence linked to the recommendation provided, caveats discussed, and barriers to implementation delineated.

Part 1 provides focused pharmacologically-based treatment guidance in a series of 26 recommendations ${ }^{8}$. The overarching principle is that remission of RA is the desired outcome and that all available therapies should be used to achieve this goal. The document outlines baseline assessments and ongoing monitoring; treatment targets; frequency of visits; and which, when, and how to use available traditional, and all current biologic DMARD. A limited role for corticosteroids is accepted. It is acknowledged that remission may be difficult to achieve and that other outcomes, such as achieving low disease activity, minimizing disability and joint damage, and improving quality of life may be more realistic outcomes in some patients ${ }^{9,10}$. Of great importance to treating physicians is that choice of outcome measure is at the rheumatologist's discretion. Ironically, the document does not include recommendations for aspirin and other nonsteroidal antiinflammatory drugs, nor nonpharmacological treatments that were considered the standard of care in 1966. It is interesting to note that the focus of the 1966 article, i.e., salicylates to avoid the toxicity of then-available DMARD, changed in 2008 to use of DMARD to avoid toxicity of salicylates (and other NSAID) ${ }^{11}$.

Part 2 provides guidance focused on 4 specific issues of safety ${ }^{12}$. Thirteen recommendations were developed addressing specific safety aspects of treatment with traditional and biologic DMARD, including (1) perioperative management, (2) screening for latent tuberculosis (TB) infection and indications for initiating TB prophylaxis, (3) optimal vaccination practices, and (4) management of patients with malignancy (active and past).

The safety recommendations are logical. They clearly direct rheumatologists to obtain a thorough baseline history of current and past malignancies. They urge assessments for TB and recommend optimal vaccination status early in the management of the patient with RA, before treatment with steroids and immunosuppressant drugs obscures interpretation of tests and diminishes response to vaccines. The advice on the management of drugs in the perioperative period and in patients with a history of malignancy is informative and the result of collaboration with experts in the fields of infectious diseases and malignancy. The only disappointment with the safety part is that it is limited to 4 issues. Advice on other safety issues, such as management of drugs in patients with concomitant cardiovascular risk factors and in patients with lung disease, as well as during pregnancy, would have been wonderful additions. The CRA should not disband the working group until a companion safety paper is produced.

An offshoot of the exercise has been the identification of many important additional questions that need to be answered. Which biologic is best overall can be answered only by direct comparison. Which biologic is best for my specific patient is a question that we hope may be answered in the future. The CRA guidelines tell us when to start drugs. We anticipate future publications that will inform us when we can stop drugs. With regard to safety, it is clear that conventional randomized controlled trials (RCT) have been inadequate in addressing many physicians' concerns. RCT are of limited duration and have excluded patients with complicated disease, thereby deliberately avoiding answering the questions that make clinical practice difficult. Many of the data used to inform the CRA recommendations on safety are derived in a retrospective manner, with all the attendant limitations. To enhance our confidence on very longterm safety, studies prospectively evaluating specified safety issues are obviously needed.

The promise of utilizing a treat-to-target philosophy is more than a reduction in the number of active joints and improvement in the Health Assessment Questionnaire. Data are accumulating on enhanced work productivity ${ }^{13}$, decreased need for joint replacement surgery, and improved cardiovascular outcomes ${ }^{14}$. For most patients with RA, these very longterm benefits cannot be achieved by simple measures, but require the services of a physician with sophisticated expertise in the use of multiple drugs, frequently under complicated circumstances.

The superb CRA recommendations will facilitate the treatment of patients with RA because they have brought clarity and have recommended actions to deal with some of the dilemmas that have perplexed treating physicians.

\author{
JACOB KARSH, MD, \\ Ottawa Hospital, Riverside Campus, \\ 1967 Riverside Drive \\ Ottawa, Ontario K1H 7W9, Canada
}

Address correspondence to Dr. Karsh; E-mail: jkarsh@ottawahospital.on.ca

\section{REFERENCES}

1. Cohen AS. A plea for conservative therapy in rheumatoid arthritis. In: Ingelfinger FJ, Relman AS, Finland M, editors. Controversy in internal medicine. Philadelphia: WB Saunders; 1966:543-51.

2. Bayles TB. Why treat rheumatoid arthritis? In: Ingelfinger FJ, Relman AS, Finland M, editors. Controversy in internal medicine. Philadelphia: WB Saunders; 1966:561-70.

3. Anonymous. Controversy one revisited: Treatment of rheumatoid arthritis. In: Ingelfinger FJ, Relman AS, Finland M, editors. Controversy in internal medicine II. Philadelphia: WB Saunders; 1966:28-9.

4. Smolen JS, Aletaha D, Bijlsma JWJ, Breedveld FC, Boumpas D, Burmester G, et al. Treating rheumatoid arthritis to target: Recommendations of an international task force. Ann Rheum Dis 2010;69:631-7.

5. Bykerk VP, Schieir O, Akhavan P, Hazlewood GS, Cheng CK, Bombardier C. Emerging issues in pharmacological management of rheumatoid arthritis: Results of a national needs assessment survey identifying practice variations for the development of Canadian Rheumatology Association clinical practice recommendations. J Rheumatol 2012;39:155-8.

6. Schieir O, Hazlewood G, Akhavan P, Bykerk V, Bombardier C. 
Time to ADAPTE: A novel methodology for the development of national clinical practice guidelines to expedite dissemination [abstract]. Ann Rheum Dis 2010;69 Suppl 3:652.

7. AGREE Collaboration. Development and validation of an international appraisal instrument for assessing the quality of clinical practice guidelines: The AGREE project. Qual Saf Health Care 2003;12:18-23.

8. Bykerk VP, Akhavan P, Hazlewood GS, Schieir O, Dooley A, Haraoui B, et al. Canadian Rheumatology Association recommendations for pharmacological management of rheumatoid arthritis with traditional and biologic disease-modifying antirheumatic drugs. J Rheumatol 2012;39:1559-82.

9. Luqmani R, Hennell S, Estrach C, Basher D, Birrell F, Bosworth A, et al. British Society for Rheumatology and British Health Professionals in Rheumatology guideline for the management of rheumatoid arthritis (after the first 2 years). Rheumatology 2009;48:436-9.

10. Scottish Intercollegiate Guidelines Network (SIGN). Management of early rheumatoid arthritis. [Internet. Accessed May 25, 2012.] SIGN publication No. 48; 2000. Available from: http://www.sign.ac.uk/guidelines/fulltext/123/index.html
11. Saag KG, Teng GG, Patkar NM, Anuntiyo J, Finney C, Curtis JR, et al. American College of Rheumatology 2008 recommendations for the use of non-biologic and biologic disease-modifying anti-rheumatic drugs in rheumatoid arthritis. Arthritis Rheum 2008;59:762-84.

12. Bombardier C, Hazlewood GS, Akhavan P, Schieir O, Dooley A, Haraoui B, et al. Canadian Rheumatology Association recommendations for pharmacological management of rheumatoid arthritis with traditional and biologic disease modifying antirheumatic drugs: Part II. Safety. J Rheumatol 2012;39: 1583-602.

13. van Vollenhoven RF, Cifaldi MA, Ray S, Chen N, Weisman MH. Improvement in work place and household productivity for patients with early rheumatoid arthritis treated with adalimumab plus methotrexate: Work outcomes and their correlations with clinical and radiographic measures from a randomized controlled trial companion study. Arthritis Care Res 2010;62:226-34.

14. Gabriel SE, Crowson CS. Risk factors for cardiovascular disease in rheumatoid arthritis. Curr Opin Rheumatol 2012;24:171-6.

J Rheumatol 2012;39:1497-9; doi:10.3899/jrheum.120407 